\title{
Pregnancy gestation at delivery and breast milk production: a secondary analysis from the EMPOWER trial
}

Elizabeth V. Asztalos ${ }^{1 *}$ (D), Alex Kiss ${ }^{2}$, Orlando P. da Silva ${ }^{3}$, Marsha Campbell-Yeo ${ }^{4}$, Shinya Ito $^{5}$, David Knoppert ${ }^{6}$ and EMPOWER Study Collaborative Group

\begin{abstract}
Background: Preterm birth alters the normal sequence of lactogenesis. Lactogenesis I may not yet have started when mothers of very preterm infants ( $\leq 29$ weeks gestation) have given birth. Preterm infants are too small or too ill to initiate suckling in the immediate postpartum period thus altering the normal cascade of event for lactogenesis II. With an increasing demand for mother's own milk as a primary source of nutritional support in the care of very small and preterm infants, mothers of these infants are often at risk of expressing inadequate amounts of milk. The use of galactogogues is often considered when mothers of preterm infants are still having challenges in breast milk production. What is not clear in the literature is the role that pregnancy gestation at birth plays in successful response to galactogogues. Our objective for this study was to evaluate the role of pregnancy gestation at birth on a mother's response to the treatment interventions in the EMPOWER trial.
\end{abstract}

Methods: For this analysis, the study participants are the 90 mothers who participated in the EMPOWER trial and were in the stratified in two gestational age groups, $23^{0 / 7}-26^{6 / 7}$ weeks and $27^{0 / 7}-29^{6 / 7}$ weeks at the time of randomization. The primary outcome measures were the proportion of mothers in each of the gestational age groupings who achieved a $50 \%$ increase in breast milk volume on day 14 and day 28 of the study treatment period.

Results: On day 14 of the study treatment, there was no significant difference in the proportion of mothers in the 2326 weeks gestation group (72.9\%) compared to those in the 27-29 weeks gestation group (64.2\%), OR 1.51 (95\% Cl 0.60, $3.78 ; p=0.38$ ). Similarly, there was no difference in the proportion of mothers between the two gestational age groupings on day 28 of the study treatment, $70.3 \%$ compared to $62.3 \%$, OR 1.43 (95\% Cl 0.58, 3.51; $p=0.43$ ).

Conclusion: This secondary analysis was able to demonstrate that mothers of very preterm infants, $<30$ weeks gestation at birth, were able to respond to the study treatment in a similar fashion regardless of gestation at birth. If non-pharmacologic approaches are unsuccessful, then a 14-day treatment of domperidone may be considered to enhance breast milk production, even in the lowest gestational ages at delivery.

Trial registration: EMPOWER has been registered at www.clinicaltrials.gov (identifier NCT 01512225) on January 10, 2012. Keywords: Breast milk production, Domperidone, Mothers of preterm infants

\footnotetext{
* Correspondence: elizabeth.asztalos@sunnybrook.ca

'Department of Newborn and Developmental Paediatrics, Sunnybrook Health Sciences Centre, University of Toronto, M4-230, 2075 Bayview Ave, Toronto, ON M4N 3M5, Canada

Full list of author information is available at the end of the article
}

(c) The Author(s). 2018 Open Access This article is distributed under the terms of the Creative Commons Attribution 4.0 International License (http://creativecommons.org/licenses/by/4.0/), which permits unrestricted use, distribution, and reproduction in any medium, provided you give appropriate credit to the original author(s) and the source, provide a link to the Creative Commons license, and indicate if changes were made. The Creative Commons Public Domain Dedication waiver (http://creativecommons.org/publicdomain/zero/1.0/) applies to the data made available in this article, unless otherwise stated. 


\section{Background}

Lactogenesis (production and establishment of breast milk) is a complex phenomenon and involves two stages $[1,2]$. Lactogenesis I begins 12 weeks prior to parturition (28 weeks gestation onwards) during which there is an increase in lactose, total proteins and immunoglobulins. The initiation of copious milk secretions is known as lactogenesis II and occurs within 48-72 h after birth and levels off after day 4 [2]. Preterm birth alters the normal sequence of lactogenesis [3]. Preterm infants are too small or too ill to initiate suckling in the immediate postpartum period thus altering the normal cascade of event for lactogenesis II. With an increasing demand for mother's own milk as a primary source of nutritional support in the care of very small and preterm infants, mothers of these infants are often at risk of expressing inadequate amounts of milk [4-6]. Although there are several approaches to assist mothers of very preterm mothers to facilitate breast milk production [7], the use of galactogogues is often considered when mothers of preterm infants are still having challenges in breast milk production [8]. What is not clear in the literature is the role that pregnancy gestation at birth plays in successful response to galactogogues.

A recent trial, EMPOWER, sought to determine whether administration of domperidone, initiated within the first 21 days after delivery, would lead to a higher proportion of mothers having a $50 \%$ increase in the volume of expressed breast milk at the end of 14 days of treatment (Group A) compared to mothers receiving a placebo (Group B) $[9,10]$. More mothers achieved a $50 \%$ increase in milk volume after 14 days receiving domperidone $(77.8 \%)$ compared to those who received a placebo (57.8\%); odds ratios [OR] 2.56; 95\% confidence interval [CI]1.02, 6.25; $p=0.04$ ) [7]. Mothers in this trial all gave birth to their preterm infants before 30 weeks gestation.

For this secondary analysis, we sought to evaluate the role pregnancy gestation at birth played in a mother's response to the treatment interventions in the trial by comparing the differences seen between the mothers of two gestational age groupings, 23-26 and 27-29 completed weeks.

\section{Methods}

\section{Trial design}

The goal of EMPOWER was to reaffirms domperidone's ability to increase breast milk volume to a clinically significant amount which required the use of a modified placebo arm. All enrolled mothers were stratified by gestational age groupings, 23-26 and 27-29 completed weeks gestation at delivery. Mothers were randomly assigned to one of two groups: Group A (domperidone $10 \mathrm{mg}$ orally three times daily for 28 days); or Group B (placebo $10 \mathrm{mg}$ orally three times daily for 14 days followed by domperidone $10 \mathrm{mg}$ orally three times daily for 14 days). The primary outcome for the trial was based on the first 14 days of the study period for both groups.

Mothers were eligible if their preterm infants were born $\leq 29$ completed weeks gestation $\left(23^{0 / 7}-29^{6 / 7}\right.$ weeks); were 8-21 days post-delivery; were pumping a minimum of 6 times a day in the 4 days prior to study entry; and, experiencing a milk volume that was $<150 \mathrm{~mL} / \mathrm{kg} / \mathrm{d}$ (based on their infant's birthweight) during the previous $72 \mathrm{~h}$ period prior to study entry or a maternal report of milk volume reduction by more than $1 / 3$ from a peak volume of the previous $72 \mathrm{~h}$. One year into the study, the inclusion criteria were felt to be too restrictive and were modified to $250 \mathrm{~mL} / \mathrm{kg} / \mathrm{d}$ or experiencing a milk volume reduction of $20 \%$ or more from a peak volume during the previous $72 \mathrm{~h}$ period prior to study entry.

The trial was conducted in 8 level III Neonatal Intensive Care units across Canada. The research ethics committee of each centre approved the study protocol. All mothers who participated provided a written informed consent before being enrolled. Because the study was utilizing an off-label indication for domperidone, the study was conducted under the Food and Drug Act of Health Canada.

Because of its pragmatic nature, the centres were encouraged to maintain their standard approach in supporting mothers as it related to the types of pumps utilized in each centre. However, for the purpose of the trial, the mothers were encouraged to pump 6-8 times in a given 24-h period. A diary was provided to the mothers for them to record their pumping times, volumes pumped, and any side effects they may experience. Mothers were encouraged to report any adverse events immediately to the study personnel. Non-pharmacologic interventions were encouraged. The trial did not collect serum prolactin.

Because of emerging concerns related to prolonged Q-Tc intervals related to domperidone at the time the study was underway, all mothers had two electrocardiograms performed during the study period: at entry and end of the study intervention period.

\section{Study participants}

For the purpose of this secondary study analysis, the study participants are those mothers who were in the stratified gestational age groups, $23^{0 / 7}-26^{6 / 7}$ weeks compared to $27^{0 / 7}-29^{6 / 7}$ weeks at the time of randomization.

\section{Outcome measures}

The primary outcome measures were the proportion of mothers in each of the gestational age groupings who achieved a $50 \%$ increase in breast milk volume on day 14 of the study treatment period regardless of which treatment arm of the trial they were allocated to.

The secondary outcome measures for each gestational age groupings were: i) the proportion of mothers who achieved a $50 \%$ increase in breast milk volume on day 28 of 
the study treatment period; ii) the mean breast milk volume on days 14 and 28 of the study treatment period; and, iii) the mean percent volume change from the start of the trial to day 14 and from day 15 to day 28 of the study treatment period.

\section{Analysis}

The analysis was carried out using SAS Version 9.3 (SAS Institute, Cary, NC, USA). Descriptive statistics were calculated for all variables of interest. Continuous measures were summarized using means and standard deviations, whereas categorical measures were summarized using counts and percentages. Where applicable, non-parametric statistics (Wilcoxon rank sum test) were utilized.

The primary outcomes were assessed between groups using a logistic regression model. Specifically generalized estimating equations with a logit link function were utilized to account for correlation among observations taken at the same site as well as multiple births by the same mother. Odds ratios were presented along with their associated 95\% confidence intervals and $p$-values. Secondary outcomes were assessed between groups using Wilcoxon rank sum tests.

\section{Results}

Between June 1, 2012 and June 30, 2015, 90 mothers were enrolled and equally allocated to the trial study arms in EMPOWER. For this secondary analysis, there were 37 mothers in the 23-26 weeks gestation group (20 in Group A and 17 in Group B) and 53 in the 27-29 weeks gestation group (25 in Group A and 28 in Group B). The mean gestational age were 25.4 weeks and 28.3 weeks respectively. Table 1 outlines the baseline characteristics of the mothers in the two groups. The two groups of mothers were similar in their characteristics except that the mothers in the 23-26 weeks gestation group had a lower rate of being delivered by cesarean section and a lower exposure to antenatal corticosteroids but were not found to be statistically significant. The mean milk volume at the start of the study treatment was similar between the two groups of mothers, $108 \pm 96 \mathrm{ml}$ for the mothers in the 2326 weeks gestation group and $126 \pm 95 \mathrm{ml}$ for the $27-$ 29 weeks gestation group.

Table 2 shows the proportion of mothers in both gestational groups who achieved a 50\% increase in expressed milk volume on day 14 of the study treatment. There was no significant difference in the proportion of mothers in the 23-26 weeks gestation group (72.9\%) compared to those in the 27-29 weeks gestation group (64.2\%), OR 1.51 (95\% CI 0.60, 3.78; $p=0.38$ ). Because mode of delivery between the groups of mothers was viewed as a potential confounder, a logistic regression was performed after controlling for the mode of delivery with the OR being $1.77(0.68,4.58 ; p=0.24)$. In addition, there
Table 1 Baseline characteristics of mothers

\begin{tabular}{|c|c|c|c|}
\hline \multirow[t]{3}{*}{ Characteristic } & $\begin{array}{l}23-26 \text { weeks } \\
\text { Gestation }\end{array}$ & $\begin{array}{l}27-29 \text { weeks } \\
\text { Gestation }\end{array}$ & \multirow[t]{3}{*}{$P$-value } \\
\hline & $N=37$ & $N=53$ & \\
\hline & n (\%) & n (\%) & \\
\hline Maternal age (yr) mean (std) & $32.3(6.6)$ & $30.9(5.4)$ & $P=0.28$ \\
\hline$(\min , \max )$ & $(19.4-44.6)$ & $(19.7-40.9)$ & \\
\hline Self-declared ethnicity & & & $P=0.67$ \\
\hline Caucasian & $23(62.2 \%)$ & $36(67.9 \%)$ & \\
\hline Black & $4(10.8 \%)$ & $6(11.3 \%)$ & \\
\hline Asian & $7(18.9 \%)$ & $9(16.9 \%)$ & \\
\hline Aboriginal/other & $3(8.1 \%)$ & $2(3.8 \%)$ & \\
\hline Smoking prior to pregnancy & $10(27.0 \%)$ & $18(34.6 \%)$ & $P=0.44$ \\
\hline Primagravida & $12(32.4 \%)$ & 19 (35.8\%) & $P=0.74$ \\
\hline $\begin{array}{l}\text { Co-Morbidities during } \\
\text { pregnancy }\end{array}$ & $N=15(41.0 \%)$ & $N=31(58.0 \%)$ & $P=0.11$ \\
\hline $\begin{array}{l}\text { Hypertension } \\
\text { (Gestational/chronic) }\end{array}$ & 2 & 10 & \\
\hline $\begin{array}{l}\text { Diabetes } \\
\text { (Gestational/Type I and II) }\end{array}$ & 2 & 6 & \\
\hline Preterm Labour & 2 & 10 & \\
\hline Chorioamnionitis & 2 & 1 & \\
\hline Antepartum haemorrhage & 3 & 7 & \\
\hline Other & 8 & 10 & \\
\hline Antenatal corticosteroids & $28(75.7 \%)$ & $48(90.57 \%)$ & $P=0.08$ \\
\hline Cesarean Delivery & $16(43.2 \%)$ & $32(60.38 \%)$ & $P=0.11$ \\
\hline Singleton Pregnancy & $33(89.2 \%)$ & $44(83.02 \%)$ & $P=0.55$ \\
\hline $\begin{array}{l}\text { Milk volume at start of start } \\
\text { of trial Mean (std) }\end{array}$ & $108(96)$ & $126(95)$ & $P=0.28$ \\
\hline
\end{tabular}

was no significant difference in the proportion of mothers who achieved a $50 \%$ increase in milk volume on day 28 of the study treatment in the 23-26 weeks gestation group (70.3\%) compared to those in the 27-29 weeks gestation group (62.3\%), OR 1.43 (95\% CI 0.58, 3.51; $p=0.43$ ). There was no difference after controlling for the mode of delivery.

Table 3 outlines the mean milk volumes on days 14 and 28 respectively which were similar for both gestational age groupings. Table 4 outlines the mean $\%$ volume change from the start of the study (day 0 ) to day 14 and also from day 15 to day 28 (end of the study treatment). Although the earlier gestational grouping demonstrates a higher per cent volume change, this was not statistically significant.

\section{Discussion}

Mothers of very preterm infants often have a delay in initiating lactogenesis II. Impaired lactogenesis II is associated with a persistent decreased breast milk volume [11]. Studies have shown that if a mother is producing $>3500 \mathrm{~mL} /$ week by the end of week 2 post- delivery, it can be expected that 
Table 2 Primary Outcome

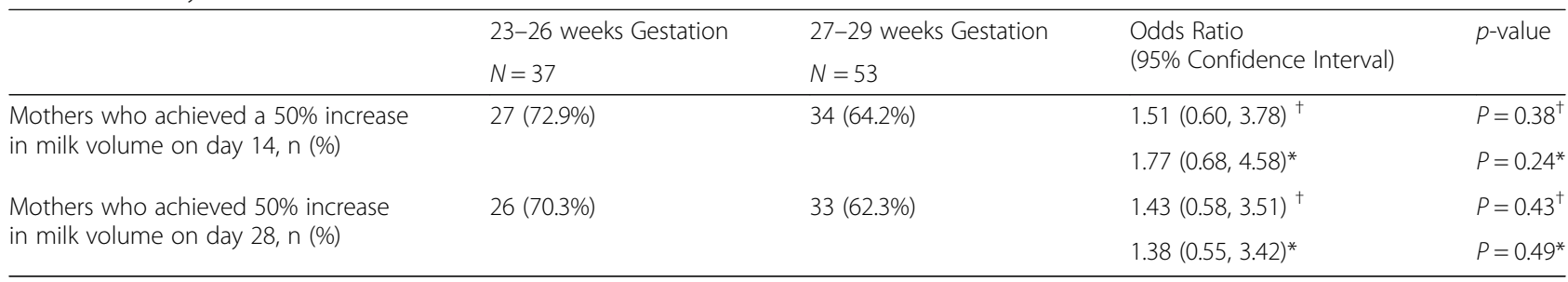

${ }^{\dagger} p$-values were based on bivariate logistic regressions

*Adjusted odds ratio and $95 \% \mathrm{Cl}$, controlling for mode of delivery

she will produce this ongoing adequate amount into weeks 4 and 5 [12]. For a mother who is producing $<1700 \mathrm{~mL} /$ week (an average of $250 \mathrm{~mL} /$ day), the outlook is grim with $100 \%$ not achieving the goal of $500 \mathrm{~mL} /$ day by weeks $4-5$ post-delivery. In this study, the mothers in both gestational age groupings had evidence of significant impairment of lactogenesis II with starting breast milk volumes for the trial easily below the $250 \mathrm{~mL} /$ day cut-off.

EMPOWER, along with previous studies, reaffirmed the effectiveness of domperidone to be considered in mothers who are experiencing challenges with milk production and require a galactogogue [13-16]. This secondary analysis shows that the response is similar between gestational age groupings regardless of whether they were started on a galactogogue earlier versus later in the trial. We were able to show that the mothers in the two gestational age groupings responded similarly to the study treatment in the EMPOWER study. Although the overall daily volume achieved did not differ between the two groups, there seemed to be a trend of improved volume as demonstrated by the $\%$ volume change in the $23-26$ weeks gestational age group though this was not statistically significant. However, this may be clinically important as it may suggest that those mothers who may not be physiologically prepared for lactogenesis II may still be able to produce breast milk in clinically adequate volumes for their infants with and without the aid of a galactogogue.

There are numerous maternal and obstetric factors which can modify how lactogenesis may occur in mothers of preterm infants [6]. Two of the more common factors include exposure to antenatal

Table 3 Secondary Outcomes: Milk Volumes

\begin{tabular}{llll}
\hline & $\begin{array}{l}\text { 23-26 weeks } \\
\text { Gestation } \\
N=37\end{array}$ & $\begin{array}{l}\text { 27-29 weeks } \\
\text { Gestation }\end{array}$ & $P$ value \\
& N=53 & \\
\hline $\begin{array}{l}\text { Mean milk volume on } \\
\text { day } 14(\mathrm{ml}) \text { (mean } \pm \text { SD) }\end{array}$ & $245.8(190.4)$ & $242.9(174.7)$ & $P=0.96$ \\
$\begin{array}{l}\text { Mean milk volume on } \\
\text { day } 28(\mathrm{ml}) \text { (mean } \pm \text { SD) }\end{array}$ & $298.5(216.0)$ & $285.3(222.9)$ & $P=0.77$ \\
\hline
\end{tabular}

Wilcoxon rank sum test corticosteroids and cesarean delivery. Cesarean delivery is associated with a number of variables which can influence how mothers of preterm infants begin pumping and initiating the cascade of events for lactogenesis [17]. Antenatal corticosteroids have been found to have an effect on reduced breast milk volumes in particular in those women who have delivered at the very preterm gestational age [3]. We did not see an effect on how mothers responded to galactogogue support in this study with either of these factors.

There are strengths and limitations to this study. The findings of this study are based on a population of mothers who were recruited for the purposes of an already published randomized controlled trial [10]. The results of this secondary analysis could be seen as having limited statistical power and be prone to bias. We were reassured that our findings were not overly biased as the two gestational age groups of mothers in the analysis were similar in characteristics and we did not see any effect from any potential confounding variables despite potentially being underpowered.

\section{Conclusions}

This secondary analysis was able to demonstrate that mothers of very preterm infants, $<30$ weeks gestation at birth, were able to respond to a galactogogue in a similar fashion regardless of gestation at birth. The use of a galactogogue can be considered if additional support in breast milk production is needed especially in the presence of optimized pumping strategies. Domperidone is, globally, the most widely used galactogogue and, where available, a 14-day

Table 4 Secondary outcomes: volume change

\begin{tabular}{llll}
\hline & $\begin{array}{l}\text { 23-26 weeks } \\
\text { Gestation } \\
N=37\end{array}$ & $\begin{array}{l}27-29 \text { weeks } \\
\text { Gestation } \\
N=53\end{array}$ & $P$ value \\
\hline $\begin{array}{l}\text { Mean \% volume change } \\
\text { day 0 to day 14 (\%) }\end{array}$ & $323.7(505.8)$ & $149.2(203.1)$ & $P=0.26$ \\
$\begin{array}{l}\text { (standard deviation) } \\
\begin{array}{l}\text { Mean \% volume change } \\
\text { day 15 to day 28 (\%) } \\
\text { (standard deviation) }\end{array}\end{array}$ & $37.9(62.8)$ & $31.9(57.1)$ & $P=0.32$ \\
\hline
\end{tabular}


treatment of domperidone may be considered to increase breast milk production, even at the lowest gestational ages at the time of delivery. For those countries where restrictions have been placed on domperidone, an alternate to domperidone, metoclopramide, can be considered.

\section{Abbreviations}

Cl: Confidence interval; ml: Milliliters; OR: Odds ratio

\section{Acknowledgments}

The authors wish to acknowledge Xinshan Cao for his dedication in providing statistical support for this project.

EMPOWER Study Collaborative Group: Christoph Fusch, McMaster University, Hamilton, Ontario, Canada; Lajos Kovacs, Jewish General Hospital, Montreal, $P Q$, Canada; Annie Janvier, Sainte-Justine Hospital, Montreal, PQ, Canada; Georges Cauotte, Centre Hospitalier Universitaire de Quebec, PQ, Canada; Abhay Lodha, Foothills Medical Centre, Calgary, AB, Canada; Barbara Bulleid, Everett Chalmers Regional Hospital, Fredericton NB, Canada; Doug McMilllan, Balpreet Singh, Izaak Walton Killam Health Centre, Halifax, NS, Canada.

\section{Funding}

EMPOWER was funded by the Canadian Institutes of Health Research (CIHR) grant MOP\# 114980. CIHR had no role in the design, management, data collection, analysis, or interpretation of the data. CIHR had no role in the writing of the manuscript or in the decision to submit for publication.

\section{Availability of data and materials}

The datasets used and/or analysed for this study are available from the corresponding author and Sunnybrook Research Institute on reasonable request.

\section{Authors' contributions}

EVA, AK, and OPdS conceptualized the study design. EVA and AK wrote or edited the manuscript for publication. AK was responsible for the statistical analysis. All authors provided critical revision of the manuscript for important intellectual design. All authors read and approved the final manuscript.

\section{Ethics approval and consent to participate}

This study was approved by the Research Ethics Board at the Sunnybrook Health Sciences Centre on December 14, 2011 (REB ID \#232-2011). The study was approved by the research ethics board of all participating institutions. Potentially eligible mothers were identified and written consent obtained.

\section{Consent for publication}

Not applicable.

\section{Competing interests}

The authors declare that they have no competing interests.

\section{Publisher's Note}

Springer Nature remains neutral with regard to jurisdictional claims in published maps and institutional affiliations.

\section{Author details}

'Department of Newborn and Developmental Paediatrics, Sunnybrook Health Sciences Centre, University of Toronto, M4-230, 2075 Bayview Ave, Toronto, ON M4N 3M5, Canada. ${ }^{2}$ Sunnybrook Research Institute, Sunnybrook. Health Sciences Centre, University of Toronto, Toronto, ON, Canada. ${ }^{3}$ Perinatal and Women's Health, London Health Sciences Centre, Western University, London, ON, Canada. ${ }^{4}$ School of Nursing, Departments of Pediatrics, Psychology and Neuroscience, Dalhousie University and Izaak Walton Killam Health Centre, Halifax, NS, Canada. ${ }^{5}$ Division of Clinical Pharmacology \& Toxicology, Department of Paediatrics, Hospital for Sick Children, University of Toronto, Toronto, ON, Canada. ${ }^{6}$ School of Pharmacy (D.K.), University of Waterloo, Kitchener, ON, Canada.
Received: 14 March 2018 Accepted: 27 August 2018

Published online: 05 November 2018

\section{References}

1. Hartmann PE. Changes in the composition and yield of the mammary secretion of cows during the initiation of lactation. J Endocrinol. 1973;59:231-47.

2. Neville MC, Morton J. Physiology and endocrine changes underlying human lactogenesis II. J Nutr. 2001;131:3005S-8S.

3. Henderson JJ, Hartmann PE, Newnham JP, Simmer K. Effect of preterm birth and antenatal corticosteroid treatment on lactogenesis II in women. Pediatrics. 2008:121(1):e92-100. https://doi.org/10.1542/peds.2007-1107.

4. Callen J, Pinelli J. A review of the literature examining the benefits and challenges, incidence and duration, and barriers to breastfeeding in preterm infants. Adv Neonatal Care. 2005;5(2):72-88.

5. Hill PD, Aldag JC, Chatterton RT, Zinaman MJ. Comparison of milk production between mothers of preterm and term mothers: the first six weeks after birth. J Hum Lact. 2005;21:22-30.

6. Sievers $\mathrm{E}$, Haase $\mathrm{S}$, Oldigs HD, Schaub J. The impact of peripartum factors on the onset and duration of lactation. Biol Neonate. 2003;83:246-52.

7. Meier PP, Johnson TJ, Patel AL, Rossman B. Evidenced-based methods that promote human milk feeding of preterm infants: an expert review. Clin Perinatol. 2017:44(1):1-22. https://doi.org/10.1016/..clp.2016.11.005. Epub 2016 Dec 27

8. Gabay PG. Galactogogues: medications that induce lactation. J Hum Lact. 2002;18:274-9.

9. Asztalos EV, Campbell-Yeo M, daSilva OP, Kiss A, Knoppert DC, Ito S. Enhancing breast milk production with Domperidone in mothers of preterm neonates (EMPOWER trial). BMC Pregnancy Childbirth. 2012;12:87. https://doi.org/10.1186/1471-2393-12-87.

10. Asztalos EV, Campbell-Yeo M, da Silva OP, Ito S, Kiss A, Knoppert D. EMPOWER study collaborative group. Enhancing human milk production with Domperidone in mothers of preterm infants. J Hum Lact. 2017;33(1): 181-7. https://doi.org/10.1177/0890334416680176. Epub 2017 Jan 20

11. Houston MJ, Howie PW, McNeilly AS. Factors affecting the duration of breast feeding: 1. Measurement of breast milk intake in the first week of life. Early Hum Dev. 1983;8:49-54.

12. Hill PD, Aldag JC. Milk volume on day 4 and income predictive of lactation adequacy at 6 weeks of mothers of non-nursing preterm infants. J Perinat Neonat Nurs. 2005;19:273-82.

13. Da Silva O, Knoppert DC, Angelini MM, Forret PA. Effect of domperidone on milk production in mothers of premature newborns: a randomized, doubleblind, placebo-controlled trial. CMAJ. 2001;164:17-21.

14. Campbell-Yeo ML, Allen AC, Joseph KS, Ledwidge JM, Caddell K, Allen VM, Dooley KC. Effect of domperidone on the composition of preterm human breast milk. Pediatrics. 2010;25:107-14. https://doi. org/10.1542/peds.2008-3441. Epub 2009 Dec 14

15. Ingram J, Taylor H, Churchill C, Pike A, Greenwood R. Metoclopramide or domperidone for increasing maternal breast milk output: a randomized controlled trial. Arch Dis Child Fetal Neonatal Ed. 2012;97:F241-5. https:// doi.org/10.1136/archdischild-2011-300601

16. Knoppert DC, Page A, Warren J, Seabrook JA, Carr M, Angelini M, Killick D, Dasilva OP. The effect of two different doses on maternal milk production. J Hum Lact. 2013;29(1):38-44. https://doi.org/10.1177/0890334412438961. Epub 2012 May 3

17. Evans KC, Evans RG, Royal R, Esterman AJ, James SL. Effect of caesarean section on breast milk transfer to the normal term newborn over the first week of life. Arch Dis Child Fetal Neonatal Ed. 2003;88:F380-2.

Ready to submit your research? Choose BMC and benefit from:

- fast, convenient online submission

- thorough peer review by experienced researchers in your field

- rapid publication on acceptance

- support for research data, including large and complex data types

- gold Open Access which fosters wider collaboration and increased citations

- maximum visibility for your research: over $100 \mathrm{M}$ website views per year

At BMC, research is always in progress.

Learn more biomedcentral.com/submission 